found statistically significant associations between pain VAS and depression score, impacts of pain on daily behaviors and between pain VAS and DAS-28. Conclusions: Almost $40 \%$ of patients had moderate to severe pain in a population of severe RA followed in hospital centers and treated with biotherapies in more than $80 \%$ of cases. Therefore, pain is still a major outcome to consider in RA. But, the proportion of patients with moderate to severe pain is less important than that one published by Taylor et al. Pain is associated with the DAS-28 score, but also with the depression score.

References:

[1] Taylor P et al. J Int Med Res 2010; 38: 1213-24.

Disclosure of Interest: None declared

DOI: 10.1136/annrheumdis-2017-eular.3287

\section{SAT0124 HIGHER BMI AND SHORTER DISEASE DURATION ARE ASSOCIATED WITH "FIBROMYALGIC" RHEUMATOID ARTHRITIS - EVALUATION USING POWER DOPPLER ULTRASONOGRAPHY}

P. Cheung, M. Lahiri. Rheumatology, National University Hospital, Singapore, Singapore, Singapore

Background: Power Doppler ultrasonography (PDUS) can differentiate RA patients who truly have active disease. Patients with persistent joint tenderness may not necessarily have true inflammation; yet composite disease activity indices remain high, leading to treatment escalation. These patients are often referred to having "fibromyalgic RA" where tender joints far exceed that of swollen joints.

Objectives: We evaluated the predictors of "fibromyalgic RA (FMRA)," defined as patient-reported tender joint count (TJC) at least 7 greater than PDUS joint count. Methods: Consecutive RA patients were recruited in a tertiary rheumatology centre in Singapore. Patients self-assessed 28 joints for tenderness, followed by blinded PDUS assessment of the corresponding joints. Patients were grouped into either, (i) PDUS joint count $>$ patient-reported TJC, (ii) PDUS joint count $=$ patient-reported TJC (iii) patient-reported TJC > PDUS joint count, (difference $<7$ ) (iv) patient-reported TJC > PDUS joint count, (difference $\geq 7$ ). Group (iv) is defined as FMRA. Predictors of FMRA were evaluated by multinomial logistic regression.

Results: Of the 101 patients, $81 \%$ were female, $72 \%$ Chinese, median age of 53.8 (IQR 48.1;62.4) and disease duration of $6.2(1.9 ; 8.8)$ years. Median BMI was $23.6(20.8 ; 27.0)$ and DAS28 was $3.2(2.5 ; 4.2)$. FMRA patients $(15 \%)$ had a high median patient-reported TJC of $13(10 ; 18)$ but low median PDUS joint count of $1(0 ; 4)$. Compared to the other groups, they had higher median DAS28 of 4.6 (3.3;5.2), shorter mean disease duration of $2.3(0.4 ; 6.8)$ years, and higher median BMI of 26.9 (23.7;32.2). No differences in mean ESR or proportion of patients with seropositive disease were observed. Using Group (i) as the reference, patients with FMRA were more likely to have a higher BMI (adjusted OR=1.6, 95\% Cl $1.2 ; 2.1, p=0.001$ for every unit increase) and shorter disease duration (adjusted $\mathrm{OR}=0.8,95 \% \mathrm{Cl} 0.7 ; 0.98, \mathrm{p}=0.03$ for every additional year). Age, gender, ethnicity, disease activity (PDUS score) and seropositivity were not significant predictors of FMRA.

Conclusions: Higher $\mathrm{BMI}$ and shorter disease duration were independent predictors of FMRA. Use of PDUS would be useful in this group, rather than basing treatment decisions on composite disease activity indices alone.

Disclosure of Interest: None declared

DOI: 10.1136/annrheumdis-2017-eular.1598

\section{SAT0125 TENOSYNOVITIS IN RHEUMATOID ARTHRITIS: PREVALENCE AND DETERMINANTS OF TENOSYNOVITIS DETECTED IN THE SONAR-ULTRASOUND EXAMINATION IN THE SCQM COHORT}

$\underline{\text { R. Micheroli }}{ }^{1}$, A. Scherrer ${ }^{2}$, L. Brulhardt ${ }^{3}$, H. Ziswiler ${ }^{4}$, P. Zufferey ${ }^{5}$, B. Möller ${ }^{6}$, A. Ciurea ${ }^{1}$, G. Tamborrini ${ }^{7} .{ }^{1}$ USZ; ${ }^{2}$ SCQM, Zurich; ${ }^{3}$ Hôpital Neuchâtelois, la Chaux-de-Fonds; ${ }^{4}$ OsteoRheuma, Bern; ${ }^{5}$ CHUV, Lausanne; ${ }^{6}$ Inselspital, Bern; ${ }^{7}$ Ultrasound Center Rheumatology, Basel, Switzerland

Background: Tenosynovitis is one of the common features of rheumatoid arthritis (RA). The diagnosis of tenosynovitis is frequently made clinically but for the detection of tenosynovitis, ultrasound (US) is more sensitive. US and $\mathrm{MRI}$ detected tenosynovitis is a predictor for unstable remission and erosive progression in RA.

Objectives: The aim of this study was to assess the prevalence and determinants of TS detected in the SONAR (Swiss Sonography Group in Arthritis and Rheumatism) examinations in patients with Rheumatoid Arthritis in the SCQM Cohort.

Methods: The SONAR ultrasound examination consists of a semi-quantitative score employing both multiplanar gray scale (B-mode) and Doppler-mode (PwD) and a TS composite score (grade $0-3$ ). Pathologic TS was defined as TS grade $2-3$. Characteristics of patients with and without TS are shown using standard descriptive methods. In a longitudinal sub-group the change in TS from no TS to pathologic TS or vice versa and DAS28 over time was categorized as "worse" ( $\triangle \mathrm{DAS} 28 \geq 2.1$ ), "same" and "better" $(\triangle \mathrm{DAS} 28 \leq-2.1)$ and the correlation between change DAS28 and in tenosynovitis was evaluated.

Results: 941 RA patients with TS score were available. $20 \%$ of included patients showed signs of TS. The presence of TS was associated with male gender and higher values of disease activity and physical function disability. Furthermore, $15 \%$ of patients in DAS28 Remission had sonographic TS. TS was less frequently observed in patients on biologic therapies (Table 1). The longitiudinal sub-group consisted of 348 patients. The correlation between change in DAS28 and change in TS was poor (polychoric correlation 0.28 [0.14, 0.43]).

Table 1. Patient Characteristics at first Tenosynovitis measurement

\begin{tabular}{|c|c|c|c|}
\hline \multirow[t]{2}{*}{ Parameter } & \multicolumn{2}{|c|}{ Tenosynovitis } & \multirow[t]{2}{*}{ OR $[95 \% \mathrm{Cl}]$} \\
\hline & Yes $(\mathrm{N}=184)$ & No $(\mathrm{N}=757)$ & \\
\hline Male gender, $\mathrm{n}(\%)$ & $59(32)^{*}$ & $158(21)^{\star}$ & $1.8[1.2,2.5]^{\star}$ \\
\hline Mean age in years & 57 & 56 & $1.0[0.99,1.02]$ \\
\hline Mean disease duration in years & 5 & 3 & $0.98[0.96,1.00]$ \\
\hline RF positive, n (\%) & $123(68)$ & $511(70)$ & $0.9[0.7,1.3]$ \\
\hline Anti-CCP positive, n (\%) & $109(65)$ & $477(70)$ & $1.1[0.6,2.1]$ \\
\hline DAS28 Remission, $\mathrm{n}(\%)$ & $24(15)^{\star}$ & $232(38)^{\star}$ & $0.3[0.2,0.5]^{*}$ \\
\hline Mean DAS28 & $3.9^{\star}$ & $3.1^{\star}$ & $1.6[1.4,1.8]^{*}$ \\
\hline Mean B-Mode SONAR Score & $12.0^{\star}$ & $8.0^{*}$ & $1.1[1.04,1.08]^{\star}$ \\
\hline Mean PD-SONAR Score & $2.0^{\star}$ & $1.0^{\star}$ & $1.0[1.06,1.12]^{\star}$ \\
\hline Mean Physician Global Assessment & $4.0^{\star}$ & $2.0^{*}$ & $1.4[1.3,1.5]^{\star}$ \\
\hline Mean HAQ Score & $0.8^{*}$ & $0.5^{\star}$ & $1.6[1.1,2.2]^{*}$ \\
\hline On biologic, $\mathrm{n}(\%)$ & $61(33)^{\star}$ & $399(53)^{*}$ & $0.4[0.3,0.6]^{*}$ \\
\hline On synthethic DMARD, n (\%) & $110(60)$ & $500(66)$ & $0.8[0.6,1.1]^{\star}$ \\
\hline
\end{tabular}

${ }^{\star} \mathrm{p}<0.05$.

Conclusions: In the SCQM RA cohort TS is associated with male gender and an overall higher disease activity. One should actively look for TS even in RA patients in DAS28 remission.

Disclosure of Interest: None declared

DOI: 10.1136/annrheumdis-2017-eular.4006

\section{SAT0126 MENTAL HEALTH BENEFITS ASSOCIATED WITH REDUCTION IN DISEASE ACTIVITY AMONG RHEUMATOID ARTHRITIS PATIENTS: A SYSTEMATIC REVIEW OF THE LITERATURE}

V. Strand ${ }^{1}$, R. Rendas-Baum ${ }^{2}$, M. Kosinski ${ }^{2}$, D. Brooks ${ }^{3}$, R. Ganguly ${ }^{3}$.

${ }^{1}$ Stanford University, Palo Alto, CA; ${ }^{2}$ Optum, Inc., Eden Prairie, MN;

${ }^{3}$ GlaxoSmithKline, Collegeville, PA, United States

Background: The association between physical functioning and rheumatoid arthritis (RA) disease activity is well established. In randomized controlled trials (RCTs) of RA treatment, reductions in disease activity result in improved physical functioning. The mental health benefits associated with reductions in disease activity are less well recognized.

Objectives: Investigate the association between reductions in RA disease activity and measures of mental health status.

Methods: A systematic review of the published literature of RCTs in RA was conducted. The search was limited to those published in the last 10 years that included the Short-Form (SF)-36 Health Survey as an outcome measure.

Results: The search strategy yielded 77 articles of which 38 were excluded for the following reasons: not RCT (23); focus exclusively on early RA (9); psychometric evaluation (4); review study (1); and off topic (1). Of the 39 articles reporting mean changes in scores on the SF-36 mental health $(\mathrm{MH})$ and role emotional $(\mathrm{RE})$ domains by treatment group, 3 articles also presented these changes in association with reductions in RA disease activity measures. ${ }^{1-3}$ In relation to American College of Rheumatology (ACR) response criteria, small to moderate (0.2-0.5 standard deviation [SD]) effect size changes in RE and $\mathrm{MH}$ domain scores were observed among RA patients whose ACR responses ranged from $20-49 \%$. Moderate to large effect sizes (0.5-0.8 SD) were reported in RE and $\mathrm{MH}$ domain change scores among ACR50 responders. Similar changes in RE and $\mathrm{MH}$ domain scores were reported by patients with reductions in Simplified Disease Activity Index (SDAI) of $\geq 10$ points.

Conclusions: The benefits of clinically meaningful reductions in disease activity among RA patients not only include improved physical functioning but also meaningful improvements in overall mental health status. The improvement in mental health is positively associated with reduction in disease activity, with only small to moderate improvements associated with less than ACR50 responses. Additional work is needed to investigate the incremental effects of RA therapies on mental health beyond the effects related to improvements in disease activity.

References:

[1] Emery P, et al. J Rheumatol. 2006;33(4):681-689.

[2] Russell AS, et al. Ann Rheum Dis. 2007;66(2):189-194.

[3] Strand V, et al. Health Qual Life Outcomes. 2014;12:31.

Disclosure of Interest: V. Strand Consultant for: Abbvie, Amgen, AstraZeneca, Biogenldec, Boehringer Ingelheim, Celltrion, Crescendo, Genentech/Roche, GSK Janssen, Lilly, Merck, Novartis, Pfizer, Regeneron, Samsung, Sanofi and UCB, R. Rendas-Baum Employee of: Optum, M. Kosinski Employee of: Optum, D. Brooks Shareholder of: GlaxoSmithKline, Employee of: GlaxoSmithKline, R. Ganguly Shareholder of: GlaxoSmithKline, Employee of: GlaxoSmithKline

DOI: 10.1136/annrheumdis-2017-eular 3568 